Research article Open Access

\title{
Comprehensive copy number profiles of breast cancer cell model genomes
}

\author{
Ashleen Shadeo and Wan L Lam
}

\author{
Cancer Genetics and Developmental Biology, British Columbia Cancer Research Centre, Vancouver BC, V5Z 1L3, Canada \\ Corresponding author: Ashleen Shadeo, ashadeo@bccrc.ca
}

Received: 12 Aug 2005 Revisions requested: 9 Sep 2005 Revisions received: 11 Oct 2005 Accepted: 18 Nov 2005 Published: 3 Jan 2006

Breast Cancer Research 2006, 8:R9 (doi:10.1186/bcr1370)

This article is online at: http://breast-cancer-research.com/content/8/1/R9

(c) 2006 Shadeo and Lam; licensee BioMed Central Ltd.

This is an open access article distributed under the terms of the Creative Commons Attribution License (http://creativecommons.org/licenses/by/2.0), which permits unrestricted use, distribution, and reproduction in any medium, provided the original work is properly cited.

\begin{abstract}
Introduction Breast cancer is the most commonly diagnosed cancer in women worldwide and consequently has been extensively investigated in terms of histopathology, immunochemistry and familial history. Advances in genomewide approaches have contributed to molecular classification with respect to genomic changes and their subsequent effects on gene expression. Cell lines have provided a renewable resource that is readily used as model systems for breast cancer cell biology. A thorough characterization of their genomes to identify regions of segmental DNA loss (potential tumorsuppressor-containing loci) and gain (potential oncogenic loci) would greatly facilitate the interpretation of biological data derived from such cells. In this study we characterized the genomes of seven of the most commonly used breast cancer model cell lines at unprecedented resolution using a newly developed whole-genome tiling path genomic DNA array.
\end{abstract}

Methods Breast cancer model cell lines MCF-7, BT-474, MDAMB-231, T47D, SK-BR-3, UACC-893 and ZR-75-30 were investigated for genomic alterations with the submegabaseresolution tiling array (SMRT) array comparative genomic hybridization $(\mathrm{CGH})$ platform. SMRT array CGH provides tiling coverage of the human genome permitting break-point detection at about 80 kilobases resolution. Two novel discrete alterations identified by array $\mathrm{CGH}$ were verified by fluorescence in situ hybridization.

Results Whole-genome tiling path array $\mathrm{CGH}$ analysis identified novel high-level alterations and fine-mapped previously reported regions yielding candidate genes. In brief, 75 high-level gains and 48 losses were observed and their respective boundaries were documented. Complex alterations involving multiple levels of change were observed on chromosome arms 1p, 8q, 9p, 11q, 15q, 17q and 20q. Furthermore, alignment of whole-genome profiles enabled simultaneous assessment of copy number status of multiple components of the same biological pathway. Investigation of about 60 loci containing genes associated with the epidermal growth factor family (epidermal growth factor receptor, HER2, HER3 and HER4) revealed that all seven cell lines harbor copy number changes to multiple genes in these pathways.

Conclusion The intrinsic genetic differences between these cell lines will influence their biologic and pharmacologic response as an experimental model. Knowledge of segmental changes in these genomes deduced from our study will facilitate the interpretation of biological data derived from such cells.

\section{Introduction}

Breast cancer is the most prevalent cancer worldwide and is the second leading cause of cancer-related deaths in women in North America [1,2]. It is a complex disease in which multiple genetic factors can combine to drive pathogenesis [3-5]. Changes in copy numbers of genes such as ERBB2 and c$M Y C$ have been extensively documented in breast cancer and are present in model cell lines [6-9]. Amplified (and overex- pressed) genes are prime therapeutic targets as for example, the use of the drug trastuzumab against ERBB2 has been shown to improve breast cancer survival rates alone or in combination with other treatments [10-12].

Strategies to detect gene copy number alterations will facilitate the identification of novel molecular targets. Previous studies with 10-megabase (Mb) resolution conventional

$\mathrm{BAC}=$ bacterial artificial chromosome; $\mathrm{CGH}=$ comparative genomic hybridization; CNA = copy number alteration; EGFR = epidermal growth factor receptor; $\mathrm{FISH}=$ fluorescence in situ hybridization; $\mathrm{kb}=$ kilobases; MAR = minimum altered region; Mb = megabases; SMRT = submegabase-resolution tiling set; SNP = single nucleotide polymorphism. 
metaphase comparative genomic hybridization (CGH) have identified gross regions of recurrent chromosomal aberrations in multiple breast cancer cell lines including loci within chromosomes 1q, 8q, 11q13,17q and 20q13. Many of these alterations proved to be relevant because they were also present in primary tumors investigated [13-15]. Recent advances in array CGH have greatly improved the resolution of this technology, enabling the detection of segmental copy losses and gains $[16,17]$. Regional genomic arrays, providing contiguous or tiling coverage of a locus of interest, have been constructed for the fine mapping of commonly altered regions in breast cancer (such as 20q13) [18-20]. Whole chromosome arrays have been used to provide information at $500 \mathrm{~kb}$ intervals. For example, a chromosome 17 array was used to identify 13 regions of change present in breast cancer cell line models and primary breast cancers [21]. Similarly, a genome-wide array containing nearly 2,500 bacterial artificial chromosome (BAC) clones with a resolution at about $1.4 \mathrm{Mb}$ was used to illustrate the detection of copy number alterations (CNAs) in various breast cancer cell lines [22]. Recently, a separate study using an array of 422 genomic loci detected frequent alterations at 1, 6, 7p, 9,11q, 12q, 17, 20q and 22q in archival breast cancer specimens [23]. cDNA arrays have also detected DNA copy changes of amplicons containing ERRB2 on $17 q$ [24-27]. More recently, a cDNA array containing 6,691 mapped human genes was used to explore the relationship between copy number alteration and gene expression changes in breast tumors and cell lines [28]. While large-insert clone megabase-interval CGH arrays and cDNA arrays provide a robust platform for the rapid survey of tumor genomes, valuable information could be overlooked as a result of their limited resolution. It is clear that a more detailed description of breast tumor genomes would require re-examination with a higher-resolution array platform.

Genetic, biochemical and pharmacologic studies of breast cancer have been greatly dependent on several commonly used model breast cancer cell lines: MCF-7, BT-474, SK-BR3, T-47D, UACC-893, MDA-MB-231 and ZR-75-30. That is, a summation of studies involving at least one of these seven cell lines produces over 13,500 hits on Medline. These cells are known to harbor gross chromosomal aberrations; measuring the precise segmental copy number status across their entire genome may uncover novel discrete changes. In the current study we expanded the use of array $\mathrm{CGH}$ to survey the genomes of these breast cancer cells at unprecedented detail with a recently developed whole-genome tiling path array that covered the genome with 32,433 overlapping BAC clones [29]. Analysis at this resolution has led to the identification of novel features in these genomes and to the delineation of segmental genetic alterations that have escaped detection by conventional molecular cytogenetic techniques and previous marker-based or interval array CGH analysis.

\section{Materials and methods Cell line DNA}

A panel of seven breast cancer-derived cell line DNA was obtained from the American Type Culture Collection: MCF-7, T-47D, Sk-Br-3, MDA-MB-231, BT-474, UACC-893 and ZR75-30. Pooled normal female DNA was used as reference for all array CGH experiments (Novagen, Mississauga, ON, Canada). DNA was quantified with a NanoDrop ND-1000 spectrophotometer (NanoDrop Technologies, Wilmington, DE, USA).

\section{Array CGH}

The seven cell lines were assayed for genetic alterations with a whole-genome tiling path BAC array in comparative genomic hybridization experiments. The submegabase-resolution tiling set (SMRT) array contains 32,433 overlapping BAC-derived DNA segments that provide tiling coverage over the human physical genome map. All clones were spotted in triplicate, resulting in 97,299 elements over two sides [29-31]. A detailed protocol is provided in Additional file 1.

\section{Imaging and analysis}

Hybridizations were scanned with an imaging system based on a charge-coupled device (Arrayworx eAuto; Applied Precision, Issaquah, WA, USA) and analyzed with SoftWoRx Tracker Spot Analysis software. Stringent criteria were applied to filter spot intensity data. A standard deviation greater than 0.075 between triplicate spots was deemed unreliable and such spots were therefore excluded from our analysis [29]. Only data points with a ratio of signal intensity to background intensity noise exceeding 15 were used in the analysis.

Custom software (SeeGH) was used to visualize $\log _{2}$ ratios of clones with respect to location in the genome [32,33]. Because of the complexity of the genomes of these cell lines with respect to ploidy, we have set thresholds for high-level gains and losses to +0.8 and -0.7 , respectively, to limit the number of regions for discussion. This threshold encompasses high-level or multi-copy changes previously reported while excluding the abundant number of low-level or singlecopy changes common to these cell lines. The complete data set has been made publicly available for further inquiry. In addition, only those loci containing two or more altered overlapping clones were included in the analysis to reduce false positives, and breakpoints were confirmed with the publicly available aCGH-smooth software [34,35].

\section{Fluorescence in situ hybridization}

For fluorescence in situ hybridization (FISH) probe synthesis, DNA samples from BAC clones RP11-118L18, RP11419H8, RP11-813P3 and RP11-790l13 were amplified with a modified ligation-mediated polymerase chain reaction protocol as described previously [31]. Imaging and analysis were performed as described previously [36]. 


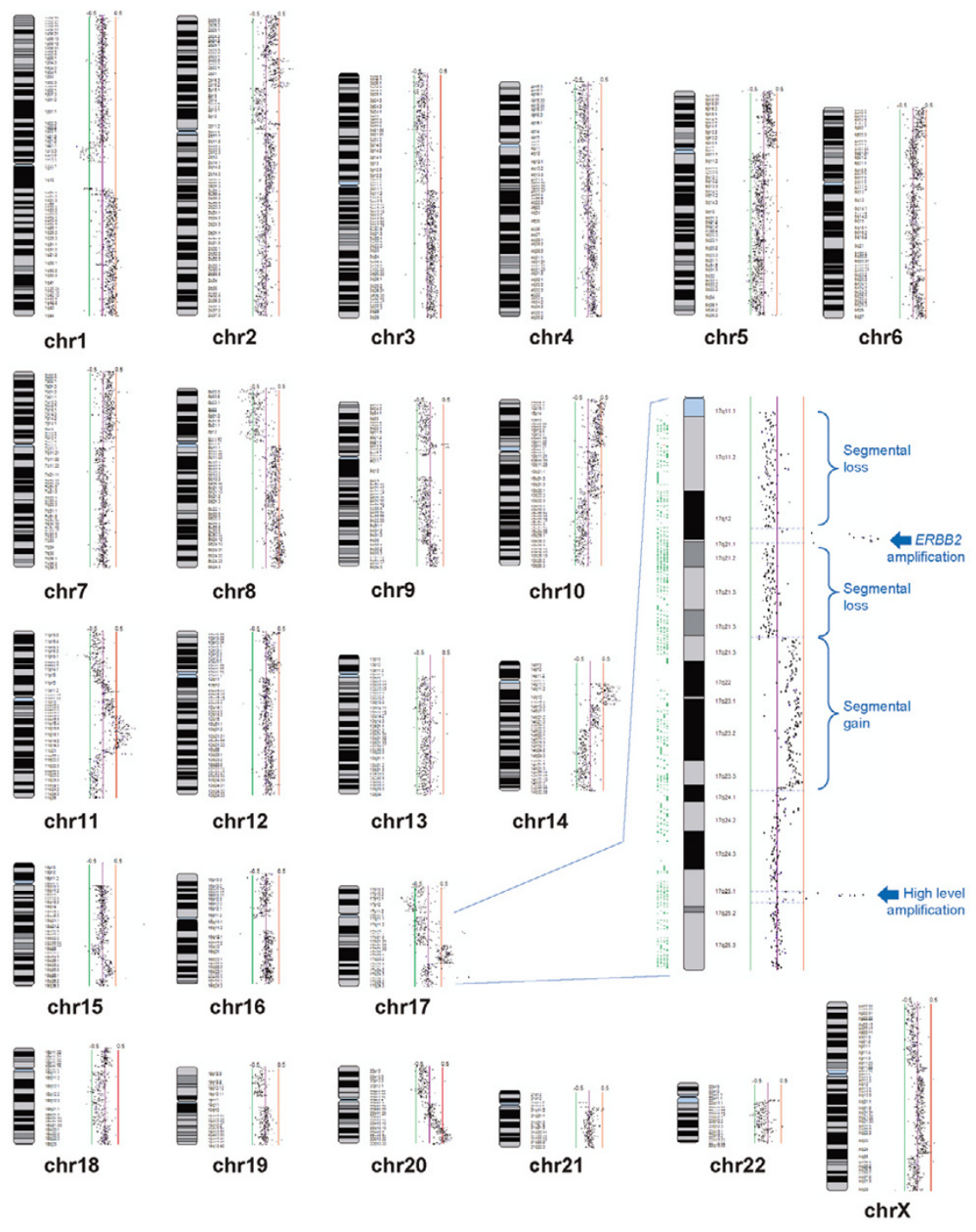

Comprehensive submegabase-resolution tiling set (SMRT) array comparative genomic hybridization profile of cell line UACC-893. Whole-genome SeeGH karyogram UACC-893. Individual data points denote $\log _{2}$ ratios plotted to corresponding chromosomal location. Log $2 \pm 0.5$ scale bars are included for reference. Displacement of data points to the right and left of the centre line represents gain and loss, respectively. The inset shows a magnified view of complex alteration on chromosome $17 \mathrm{q}$.

\section{Results and discussion \\ Whole-genome tiling path analysis of segmental alterations}

SMRT array CGH technology provides a tool for assessing genomic aberrations comprehensively in great detail. Comprehensive genomic profiles of segmental gains and losses for seven commonly used breast cancer model cell lines were revealed with this technology. Because of the large amount of data generated, we present the complete genomic profiles and frequency analysis in Additional files 2, 3, 4, 5, 67 and 8 (Figure 1). The raw data of the signal intensity ratios of the 97,299 spots for each array CGH experiment have been made publicly available [33] and also deposited at the gene expres- sion omnibus (GEO) database at $\mathrm{NCBI}$, series accession number GSE3106.

Figure 1 demonstrates the details of a tiling path SeeGH karyogram, summarizing SMRT array CGH results for cell line UACC-893. Whole chromosomal arm gains can be seen at $1 q, 5 p, 7 p, 8 q$ and $10 p$, whereas arm losses are evident at 3p, $4 p, 5 q, 8 p, 13 q, 17 p, 19 p, 20 p$ and Xp. Smaller segmental changes such as the telomeric gained region of $6 p$ or loss at $10 q$ are readily detected. Complex alterations indicating multiple levels of change are denoted by higher-level peaks embedded within a region of change, for example the central region of the $2 p$ arm. The magnified display of $17 q$ demonstrates the 
identification of a discrete CNA. Beginning at the centromere, we can see two regions of segmental loss separated by a high-copy-number amplicon containing the ERBB2 gene. The centromeric breakpoint of this amplicon is located between the overlapping regions of clones RP11-25P3 and RP11$592 \mathrm{~L} 16$, whereas the telomeric breakpoint is located between clones RP11-686E5 and RP11-259G21. The second region of segmental loss at $17 q 21.1-q 21.31$ is followed by a large segmental gain and a second discrete multiple copy amplification at $17 \mathrm{q} 25.1$.

To establish detection sensitivity, we first examined previously reported regions of CNA. Our data indicated high-level gains at the c-MYC locus in SK-BR-3 and MCF-7 (+2.84 and +1.19 $\log _{2}$ ratios, respectively) corresponding to previously reported change in copy number $[7,37,38]$. Similarly, BT-474, ZR-7530, UACC 893 and SK-BR-3 are known to harbor a high-level amplification of the ERBB2 locus. SMRT array CGH, in addition to detecting the ERBB2 locus, revealed several additional discrete changes on the $17 q$ arm in these cell lines. In another example, a previously reported homozygous deletion at $3 q 13.31$, detected by a $10 \mathrm{~K}$ single nucleotide polymorphism (SNP) array in MCF-7, yielded a $\log _{2}$ ratio of -1.2 in our SMRT array CGH analysis [39]. Further comparison of SNP data and SMRT array CGH for cell line BT-474 showed that many of the alterations detected by SMRT array CGH were not clearly delineated or were not detected by the SNP platform (Additional file 9). Although SNP arrays offer the advantage of genotype data, they are only suited to the detection of large-scale changes in copy number. However, the two technologies are clearly complementary because each is designed to address a different question.

Six of the seven cell lines (not MDA-MB-231) were previously profiled for genomic alterations with the use of a 6,691-gene cDNA microarray [28]. Pollack and colleagues showed numerous genomic alterations, both gains and losses, which were correlated with expression patterns on the same array platform. All the CNAs reported were detected by SMRT array $\mathrm{CGH}$, along with the discovery of numerous novel alterations when re-evaluated at tiling path resolution. Known and novel CNAs for the seven genomes are summarized in Table 1. Interestingly, not all CNAs contain annotated genes, which is consistent with the fact that the annotation of coding and noncoding transcripts within the human genome sequence is a continuing process.

\section{Novel features of the genome of model cell lines}

Among the seven cell lines, 75 regions of high-level (multicopy) segmental gains and 48 regions of multi-copy loss were identified. Because these cell lines serve as model systems for investigating breast cancer biology, a detailed understanding of their genetic alterations is essential to the interpretation of studies with these cell lines. We first describe noteworthy fea- tures of the individual genomes and then compare across multiple profiles to identify common alterations.

MCF-7 genome

The MCF-7 genome harbors 21 high-level CNAs, summarized in Table 1. Remarkably, many of the previously reported regions of genetic alteration split into multiple segments upon tiling resolution analysis. The $1 \mathrm{p} 13$ amplification described previously [40] in fact divides into three distinct segments of high-level amplifications: a 1,300 kb segment at 1p13.3, containing only two genes, those encoding arginine $\mathrm{N}$-methyltransferase-6 (PMRT6) and netrin G1 (NTNG1); a $300 \mathrm{~kb}$ segment at $1 \mathrm{p} 13.2$, encompassing a single gene, that encoding potassium voltage-gated channel subfamily $D$ member (KCND3); and a 1,300 kb region at the centromeric end of 1p13.2, containing 20 genes including BCAS2, which has been shown to be amplified and overexpressed in breast cancer cell lines and tumors (Figure 2) [40-42]. Although a loss at $4 p 15-$ gter has been reported [14], we observed a $7 \mathrm{Mb}$ loss at $4 q 34.3-q 35.2$. The same group also reported an $11 p$ loss; however, our data show that this alteration represents a large $45 \mathrm{Mb}$ segment at 11p15.5-p11.2 and an adjacent but distinct $2 \mathrm{Mb}$ loss at 11p11.2. Similarly, amplifications at the distal end of $15 \mathrm{q}[13,14]$ were fine mapped to reveal a $4.9 \mathrm{Mb}$ high-level gain at 15q21.1-q21.3 encompassed by clones RP11-416B20 and 664B9 containing FGF7, CYP19A1 and MAPK6. A lower-level gain was also observed at $15 q 22.2$ qter.

\section{BT-474 genome}

BT-474 possesses the greatest number of high-level gains and complex alterations and has previously been profiled with the SMRT array CGH platform [29]. In brief, the 1q arm showed multiple rearrangements. A complex aberration at 1q21.2-q25.1 is highlighted by three peaks of high-level gain: 1q21.2-q21.3 (350 kb), 1q22-q23.1 (500 kb) and 1q24.2 $(550 \mathrm{~kb})$. In addition, two previously undocumented, distinct regions of gain were identified at 1q31.3 $(1,650 \mathrm{~kb})$ and 1 q32.1 (950 kb). Figure 3a shows FISH verification of the 1 q32.1 amplicon. Although a 1q42-qter gain has been previously reported for BT-474 [14] we observed four separate regions of high-level gain: 1q42.12-q42.13 (500 kb), 1q43 (450 kb), 1q44-q43 (850 kb) and 1q44 (1,700 kb). A 11q13q14 gain was redefined by SMRT array CGH as a complex high-level amplification at 11q13.1-13.5 (19.8 Mb) containing two distinct and localized high-level peaks at 11q13.1 (700 $\mathrm{kb})$ and 11q13.4 (1,050 kb).

In addition to fine mapping of regions previously reported, several prominent novel alterations were detected: high-level gains at $4 \mathrm{q} 21.1(2,700 \mathrm{~kb}), 9 \mathrm{p} 13.3(2,050 \mathrm{~kb}), 11 \mathrm{q} 22.1$ q22.2 (3,600 kb), 14q11.2-q21.1 (21 Mb) and 14q31.3q32.12 $(3,100 \mathrm{~kb})$. Gains of $20 \mathrm{q}$ have been well documented in breast cancer $[13,20,23,43]$. In BT-474 we observed four distinct segments with increased copy numbers: $20 q 11.22$ 
Table 1

\begin{tabular}{|c|c|c|c|c|c|c|c|c|c|}
\hline Cell line & Locus & Start clone & End clone & Size (kb) & & Locus & Start clone & End clone & Size $(k b)$ \\
\hline \multirow[t]{8}{*}{ MCF7 } & Amplifications & & & & & Deletions & & & \\
\hline & $1 \mathrm{p} 13.3$ & N0451I14 & N0228E23 & 1,290 & & $3 q 13.31$ & N0747H24 & $\mathrm{N} 0362 \mathrm{H} 11$ & 700 \\
\hline & $1 \mathrm{p} 13.2$ & No099M15 & N0795O09 & 288 & & $4 q 34.3-35.2$ & N0442N05 & N0746B09 & 7,100 \\
\hline & $1 \mathrm{p} 13.2$ & N0626F04 & N0517B05 & 1,330 & & $6 q 25.2-27$ & M2007C03 & M2258B24 & 14,400 \\
\hline & $3 p 14.2-14.1$ & N0669F02 & N0589G04 & 3,180 & & $8 p$ arm & $\mathrm{p}$ & $\mathrm{p}$ & $\mathrm{p}$ \\
\hline & $8 q 21.2-q 24.21$ & N0133G02 & N0315E09 & 43,300 & & $11 p 15.5-11.2$ & N0412M16 & M2326E01 & 45,300 \\
\hline & $15 q 21.1-21.3$ & N0416B20 & N0664B09 & 4,930 & & $11 \mathrm{p} 11.2$ & N0070A09 & M2326E01 & 1,940 \\
\hline & $17 q 23.2-24.3$ & N0716B04 & N0203A19 & 113,200 & & $11 q 11-q 12.1$ & No010E21 & F0627I09 & 4,300 \\
\hline \multirow[t]{4}{*}{ Peak: } & $17 q 23.2$ & N0760B22 & N0433B24 & 4,900 & & $11 q 14.2-23.3$ & N0282G16 & N0004N09 & 30,000 \\
\hline & $17 q 25.1$ & N0076G04 & N0552F03 & 766 & & 11q23.3-25(tel) & N0196E01 & N0715D10 & 15,400 \\
\hline & $20 q 12$ & N0385G02 & N0476P15 & 1,790 & & $13 q 14.2-34($ tel) & N0155D15 & M2323L19 & 66,900 \\
\hline & $20 q 13.12-20 q 13.33$ (tel) & N0272C13 & N0476l15 & 17,500 & & & & & \\
\hline \multirow[t]{5}{*}{ Peaks: } & $20 q 13.12-20 q 13.13 \boldsymbol{A}$ & N0702EO3 & N0730O2O & 1,790 & & & & & \\
\hline & $20 q 13.13 B$ & N0711MO6 & F0592G15 & 309 & & & & & \\
\hline & $20 q 13.2 \mathrm{C}$ & N0020J08 & N0346B03 & 1,450 & & & & & \\
\hline & $20 q 13.31 D$ & N0044A06 & N0671P16 & 411 & & & & & \\
\hline & 21q22.13-22.3(tel) & N0094J12 & N0457P07 & 8,450 & & & & & \\
\hline \multirow[t]{16}{*}{ BT474 } & Amplifications & & & & & Amplifications & & & \\
\hline & $1 q 21.2-q 25.1$ & & & & & $15 q 11.2-q 12$ & $\mathrm{~N} 0607 \mathrm{H} 20$ & N0208F21 & 5,030 \\
\hline & $1 q 21.2-q 21.3 A$ & No035F14 & No714NO2 & 366 & Peaks: & $15 q 11.2 \mathrm{~A}$ & N0552D03 & M2200G17 & 949 \\
\hline & $1 q 22-q 23.1 B$ & N0647N2O & No740J19 & 510 & & $15 q 11.2 B$ & N0484P15 & N0710LO6 & 624 \\
\hline & $1 q 24.2 C$ & N0137J06 & N0616K15 & 540 & & $17 q 12-21.2$ & N0196P12 & N0278E15 & 4,090 \\
\hline & $1 q 31.3$ & N0662E13 & N0141E20 & 1,661 & & $17 q 21.32-23.2$ & N0771D19 & M2014K24 & 13,800 \\
\hline & $1 q 32.1$ & N0783D13 & N0617D19 & 936 & Peaks: & $17 q 21.32-q 21.33 \mathrm{~A}$ & NoO71G24 & No607H13 & 2,500 \\
\hline & $1 q 42.12-q 42.13$ & M2185P06 & M2016D17 & 500 & & $17 q 22-23.2 B$ & N0515J2O & N0473G17 & 2,180 \\
\hline & $1 q 43$ & N0236L13 & N0614N14 & 449 & & $17 q 23.2 \mathrm{C}$ & N0399018 & N0767P09 & 1,170 \\
\hline & $1 q 44-q 43$ & N0440F10 & N0794A13 & 865 & & $17 q 24.1-24.3$ & N0583F02 & N0693H11 & 5,300 \\
\hline & $1 q 44$ & N0778E23 & N0071K05 & 1,720 & Peak: & $17 q 24.1$ & N0583F02 & N0394K10 & 482 \\
\hline & $4 p 16.1-15.33$ & N0270I03 & N0652B07 & 1,210 & & 19p13.2-13.12 & N0295M02 & N0441D06 & 6,310 \\
\hline & $4 q 21.1$ & N0598G02 & N0772N01 & 2,700 & & $20 p 12.1$ & N0134G22 & No022E15 & 800 \\
\hline & $9 \mathrm{p} 13.3$ & N0069E18 & N0795P12 & 2,060 & & $20 q 11.22$ & N0601G07 & N0552G16 & 1,300 \\
\hline & $9 q 33.1-34.13$ & M2248M11 & N0738I14 & 12,600 & & $20 q 13.11-13.32$ & N0809G24 & N0261P09 & 14,800 \\
\hline & $11 q 13.1-13.5$ & N0813P09 & N0360N22 & 19,800 & & $20 q 13.33$ & N0648D07 & N0694l10 & 305 \\
\hline \multirow[t]{6}{*}{ Peaks: } & $11 q 13.1 \mathrm{~A}$ & No029K11 & N0804F01 & 704 & & 20q13.33-tel & N0305P22 & N0134L13 & 1,380 \\
\hline & $11 q 13.4 B$ & No093M11 & N0598G03 & 1,030 & & Deletions & & & \\
\hline & 11q22.1-22.2 & N0795D03 & N0347H03 & 3,560 & & $5 q 14.1-14.3$ & N0129E04 & N0291O24 & 5,390 \\
\hline & $14 q 11.2-q 21.1$ & N0597A11 & N0254B15 & 21,230 & & $6 q 24.1$ & N0709J21 & M22024J17 & 3,200 \\
\hline & $14 q 31.3-32.12$ & N0771008 & N0325L17 & 3,080 & & $20 q 11.22$ & N0171G22 & N0774C15 & 670 \\
\hline & & & & & & $20 p 11.23-13.11$ & N0712N14 & N0464F07 & 7,140 \\
\hline \multirow[t]{2}{*}{ ZR 7530} & Amplifications & & & & & Amplifications & & & \\
\hline & $8 q 11.21$ & N0569108 & N0513013 & 682 & & $17 q 22-23.2$ & N0349F01 & N0153J08 & 5,600 \\
\hline
\end{tabular}


Table 1 (Continued)

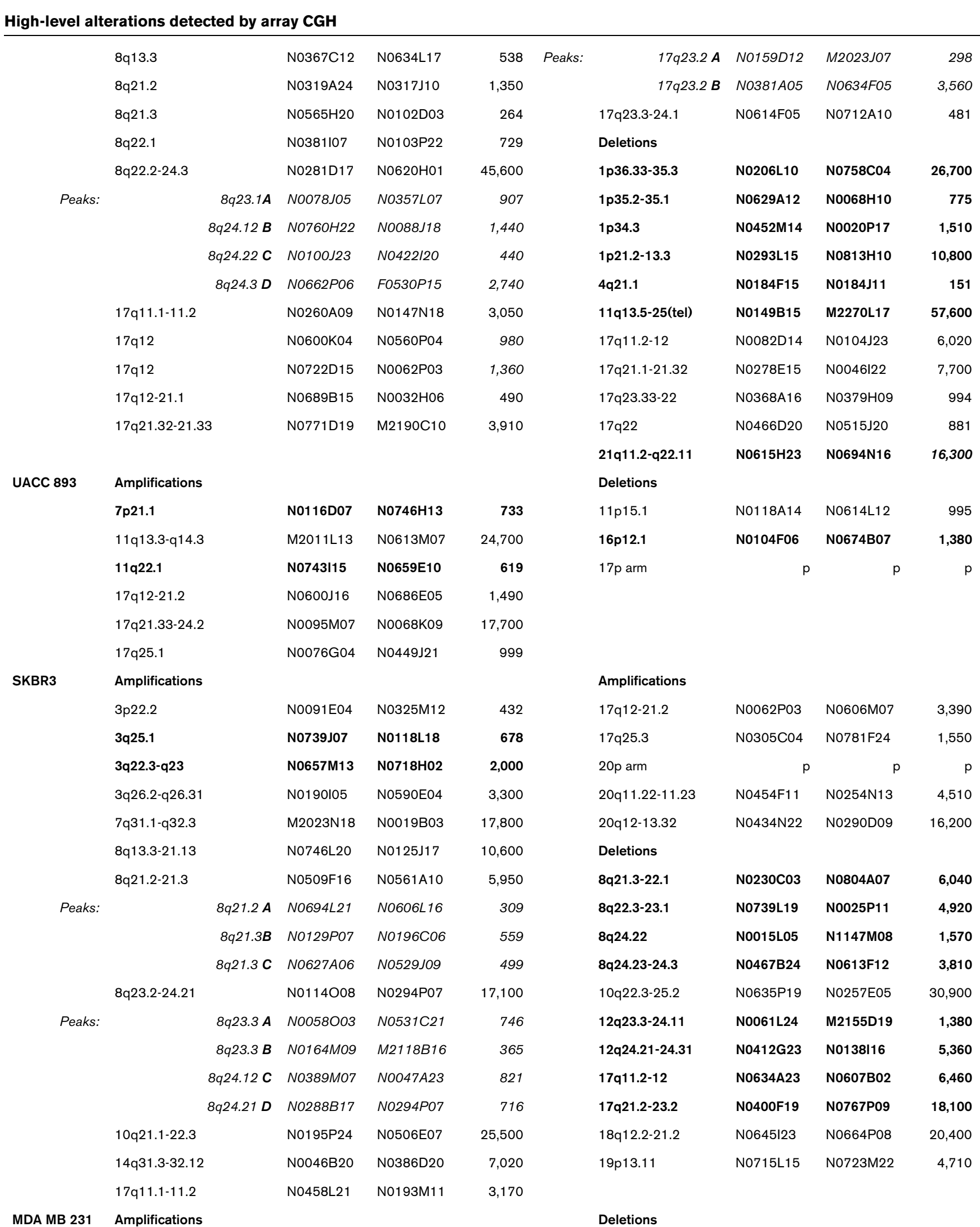




\begin{tabular}{llllllll}
\hline High-level alterations detected by array CGH & & & & & & \\
\hline
\end{tabular}

High-level peaks within complex alterations are denoted by italics. Alterations not previously characterized are in bold. Clones beginning with No or FO belong to the Roswell Park Cancer Institute libraries 11 and 13 (RP11 and RP13), respectively; those beginning with M belong to the Caltech-D (CTD) library.

(1.3 Mb), 20q13.11-q13.32 (14.8 Mb), 20q13.33 (300 kb) and 20q13.33-tel (1.4 Mb). The gene encoding prefoldin 4 (PFDN4) located within 20q13.11-13.32 has been shown to be overexpressed in those cell lines in which it is amplified, including BT-474 [18]. This chromosome arm also harbors regions of loss at $20 \mathrm{q} 11.22(650 \mathrm{~kb})$ and $20 \mathrm{q} 11.23-13.11$ $(7,150 \mathrm{~kb})$ that have not previously been reported.

\section{ZR-75-30 genome}

In total, 11 high-level losses and 13 high-level gains were identified in ZR-75-30. Multiple discrete alterations were observed on chromosome arms frequently implicated in breast cancer, including $1 p$ (four deletions), $8 q$ (eight amplicons) and $17 q$ (seven amplicons and four deletions). Novel segmental losses of varying sizes were detected at 4q21.1 (150 kb), 11q13.5qter (57.6 Mb) and 21q11.2-q22.11 (16.3 Mb). The discrete high-level amplifications on $8 \mathrm{q}$ at $8 \mathrm{q} 11.21$ (700 kb), 8q13.3 (500 kb) and 8q22.1 (700 kb) encompassed interesting gene loci such as those for the following: protein kinase DNA-activated catalytic subunit (PRKDC), which might have a role in DNA repair and non-homologous DNA end joining; transient receptor potential cation channel $\mathrm{A} 1$ (ANKTM1), which when overexpressed, affects normal eukaryotic cell growth; and cadherin 17 ( $C D H 17)$, which shares structural features with the cadherin superfamily of calcium-dependent cell-cell adhesion proteins [44-47].

\section{UACC 893 genome}

High-level gains at 11q13-q14 have been documented in UACC 893 [14]. We also observed this alteration (11q13.3q14.3, 24.7 Mb); however, an additional discrete high-level gain at $11 \mathrm{q} 22.1(600 \mathrm{~kb})$ was also discovered, which interrupts a portion of the gene locus for contactin 5 (CNTN5), a neural adhesion molecule. A novel gain at 7p21.1 (700 kb) was also detected that encompasses several gene loci, including those for anterior gradient 2 (AGR2) and breast cancer membrane protein (BCMP1). AGR2 has been shown to be positively correlated with estrogen receptor expression and negatively with epidermal growth factor receptor expression in breast cancer tissue [48]. A loss at 16p12.1 (1,400 kb) was also observed.

\section{SK-BR-3 genome}

Amplifications at 3p22-pter in SK-BR-3 have previously been reported [13,14]. We observed a $400 \mathrm{~kb}$ amplification at 3 p22.2 as well as two novel regions of high-level amplification at $3 q 25.1$ (700 kb) and 3q22.3-q23 (2,000 kb). Figure $3 b$ shows FISH confirmation of this amplification. Genetic alterations of $8 q$ seem to be complex in SK-BR-3. We observed the three previously reported regions of gain at $8 q 13.2-q 21.13$ (10.6 Mb), 8q21.2-q21.3 (6 Mb) and 8q23.2-q24.21 (17 Mb). However, we also identified three distinct amplicons within the $6 \mathrm{Mb}$ region (8q21.2 (300 kb), 8q21.3 (550 kb) and 8q21.3 $(500 \mathrm{~kb}))$ and also four distinct high-level peaks within the 17 Mb gain described above: 8q23.3 (750 kb), 8q23.3 (350 kb), $8 q 24.12(800 \mathrm{~kb})$ and $8 \mathrm{q} 24.21$ (700 kb, contains c-MYC). We also observed four regions of deletion not previously reported on 8q: 8q21.3-q22.1 (6 Mb), 8q22.3-q23.1 (4.9 $\mathrm{Mb}$ ), 8q24.22 (1.6 Mb) and 8q24.23-q24.3 (3.8 Mb). In addition to losses on chromosomes 3 and 8 , our analysis has also identified novel regions of loss at 12q23.3-q24.11 (1.4 Mb) and $12 q 24.21-q 24.31(5.4 \mathrm{Mb})$ and further delineated a $17 q 12$ gain into two distinct high-level gains at 17q11.1-11.2 (3.2 Mb) and 17q12-21.2 (3.4 Mb). In addition a previously reported gain of $17 q 24$-qter fine mapped to a $1,550 \mathrm{~kb}$ amplicon at $17 q 25.3[13,14]$.

\section{$M D A-M B-231$ genome}

MDA-MB-231 possessed the fewest number of high-level alterations. Gains at $6 p$ have previously been reported $[14,49]$; however, two distinct regions of high-level gain were observed within this arm in our analysis: at 6p21.31-21.2 (3.5 
Figure 2

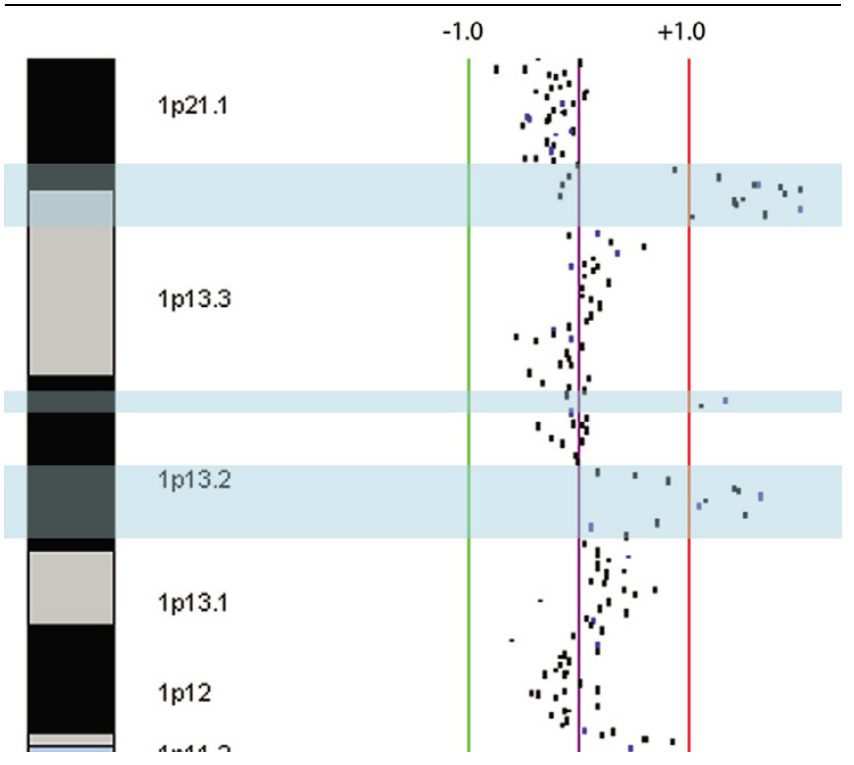

Magnified submegabase-resolution tiling set (SMRT) array comparative genomic hybridization profile of the 1p21.1-p11.1 region in MCF-7. Scale bars labelled \pm 1 denote $\log _{2}$ ratio scale. Blue highlighted regions indicate the locations of independent amplicons.

$\mathrm{Mb}$ ) and at $6 \mathrm{p} 21.2-21.1$ (3.3 Mb). We also observed a novel $670 \mathrm{~kb}$ gain at $7 q 35$. Loss at $9 p$ has also been reported; however, we were able to discern two distinct segmental losses each containing an amplicon [49-51].

\section{T-47D genome}

$\mathrm{T}-47 \mathrm{D}$ was unique in that it possessed three times as many genomic losses as gains. We observed gains at 18p11.32p11.32 (350 kb) and 18q21.1 (300 kb) that have not previously been reported $[14,38,49,51]$. Only five genes reside within the 18q21.1 region: that encoding protein inhibitor of activated STAT2 (PIAS2), elongin genes TCEB3L2 and TCEB3L and hypothetical genes DKFZP564D1378 and HSPC039.

\section{Common regions of copy number alteration}

Gains at $8 q, 17 q$ and $20 q$ are among the most frequently documented alterations in breast cancer. Eight of the nine cell lines (MDA-MB-231 was the exception) showed high-level gains at one or more of these chromosome arms. Multiple alignment of genomic profiles delineated novel minimum altered regions (MARs) common to these cell lines.

Gains at $8 q$ are arguably the most frequently documented alteration in a variety of cancers including breast and prostate cancer [5]. We have highlighted four that were common to multiple cell lines (Additional file 10). First, a discrete $500 \mathrm{~kb}$ amplicon at 8q13.3 in ZR-75-30 is also included within the larger alteration at $8 q 13.33-q 21.13$ in SK-BR-3. Only one gene resides within this MAR: that encoding transient receptor potential cation channel subfamily $\mathrm{A}$, member 1 (TRAPA1). Hyman and coleagues [26] investigated 14 breast cancer cell lines including BT-474, MCF7, SK-BR-3, T47D and ZR-75-30 with a $13 \mathrm{~K}$ cDNA array identifying four independent genomic amplicons at 8q, including 8q21.11-q21.13, 8q21.3, 8q23.3$q 24.14$ and $8 q 24.22$. However, the distinct amplicon at 8 13.3 in ZR-75-30 detected by SMRT array CGH was missed in this study. We observed a second larger MAR at 8q21.2-q21.3 common to alterations in MCF7 and SK-BR-3. About 20 genes reside in this $5 \mathrm{Mb}$ region, including those encoding E2F transcription factor, exonuclease GOR and matrix metalloproteinase 16. A third MAR is located at 8q24.12-q24.21 and is common to MCF-7, ZR-75-30 and SK-BR-3, whereas lower-level gains are apparent in BT-474, UACC-893 and MDA-MB-231. Although the genes encoding zinc finger transcription factor (TRPSI) and eukaryotic translation initiation factor 3 (EIF3S3) are excluded from this MAR (c-MYC is included), some of the cell lines possess highly complex gains that extend through a much larger region of the arm and can include the TRPSI and EIF3S3 loci. Savinainen and colleagues [37] reported 41 copies of TRPS1 and 21 copies of EIF3S3 and MYC in Sk-Br-3. The fourth and most telomeric MAR, 8q24.3, has boundaries defined by a peak of high-level change within the large complex alteration 8q22.2-q24.3 found in ZR-75-30. MCF-7, BT-474 and UACC-893 share low-level gains within this region of about 10 genes.

Chromosome $17 q$ gains have been well documented in both breast cancer cell lines and clinical cases $[14,15,21,39,50,52]$. Re-examination of this chromosome arm at tiling resolution suggests that the $17 q$ amplification is complex and involves multiple but distinct regions (Fig. 4). First we identified a common high-level gain at 17q25.1 containing a narrow MAR of $760 \mathrm{~kb}$ bounded by BAC clones RP11-76G4 and RP11-552F3. The genes encoding RECQ protein-like 5 (RECQL5), $\mathrm{H} 3$ histone family $3 \mathrm{~B}(\mathrm{H} 3 \mathrm{~F} 3 \mathrm{~B})$ and growth factor receptor-bound protein 2 (GRB2) reside within this gene-rich region, with GRB2 shown to interact with epidermal growth factor receptor (EGFR) [53]. Second, at 17q23, two separate amplicons in MCF-7 and one large amplicon in BT-474 have been described previously, although it is unclear whether these amplicons are overlapping and harbor the same candidate oncogene [25,54]. Our data show the presence of a large complex alteration in MCF-7 at 17q21.32-q24.3 with a high-level amplification at 17q23.2. BT-474 contained two regions of complex alterations at 17q21.32-q23.2 comprising three distinct high-level peaks as well as a single peak at 17q24.1-q24.3 with a single peak. Similarly, three regions of high-level gains were observed in ZR-75-30 and one large region of lower-level gain in UACC-893. Interestingly, our alignment revealed that the high-level peaks involving the $17 q 23.2$ region in MCF-7, BT-474 and UACC893 do overlap, defining a $800 \mathrm{~kb}$ MAR from RP11-50F16 to RP11-653P10 
Figure 3

(a)

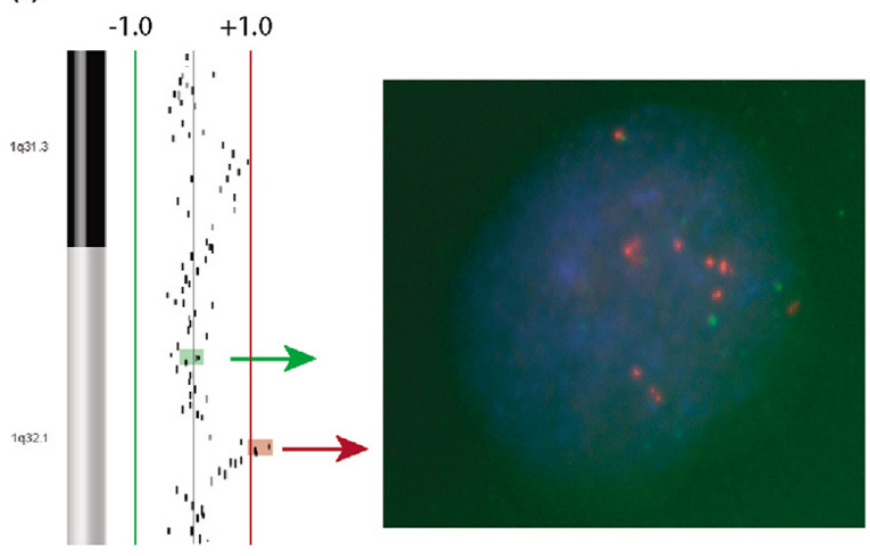

(b)

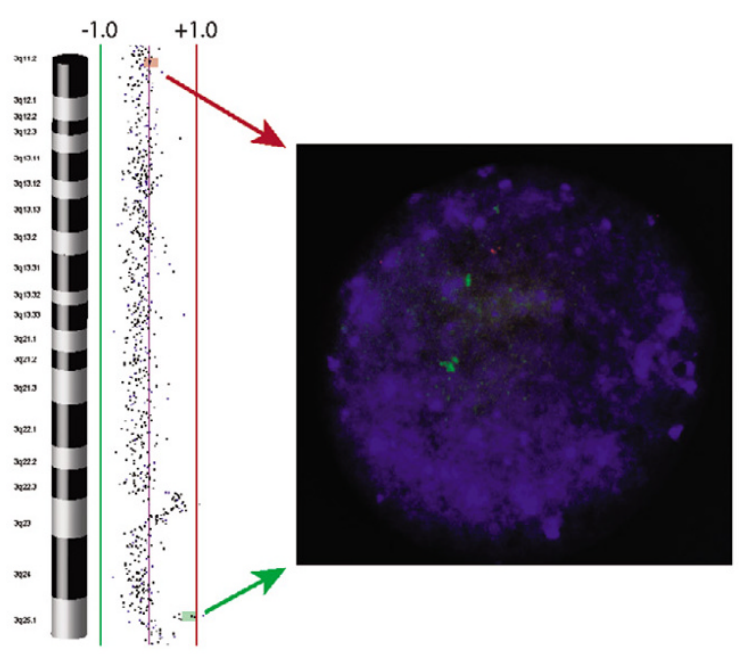

Fluorescence in situ hybridization (FISH) analysis in SK-BR-3 and BT-474 cells. (a) SK-BR-3 interphase FISH. Clone RP11-118L18, labeled in spectrum green, is located within a $680 \mathrm{~kb}$ amplicon at 3q25.1; clone RP11-419H08, labeled in spectrum red, denotes an unchanged site at 3q11.2. (b) BT-474 interphase FISH. Clone RP11-813P03, labeled in spectrum red, is located at the peak of a $940 \mathrm{~kb}$ amplicon at $1 \mathrm{q} 32.1$; clone RP11-790l13, labeled in spectrum green, is located within an adjacent unchanged region.

\section{Figure 4}

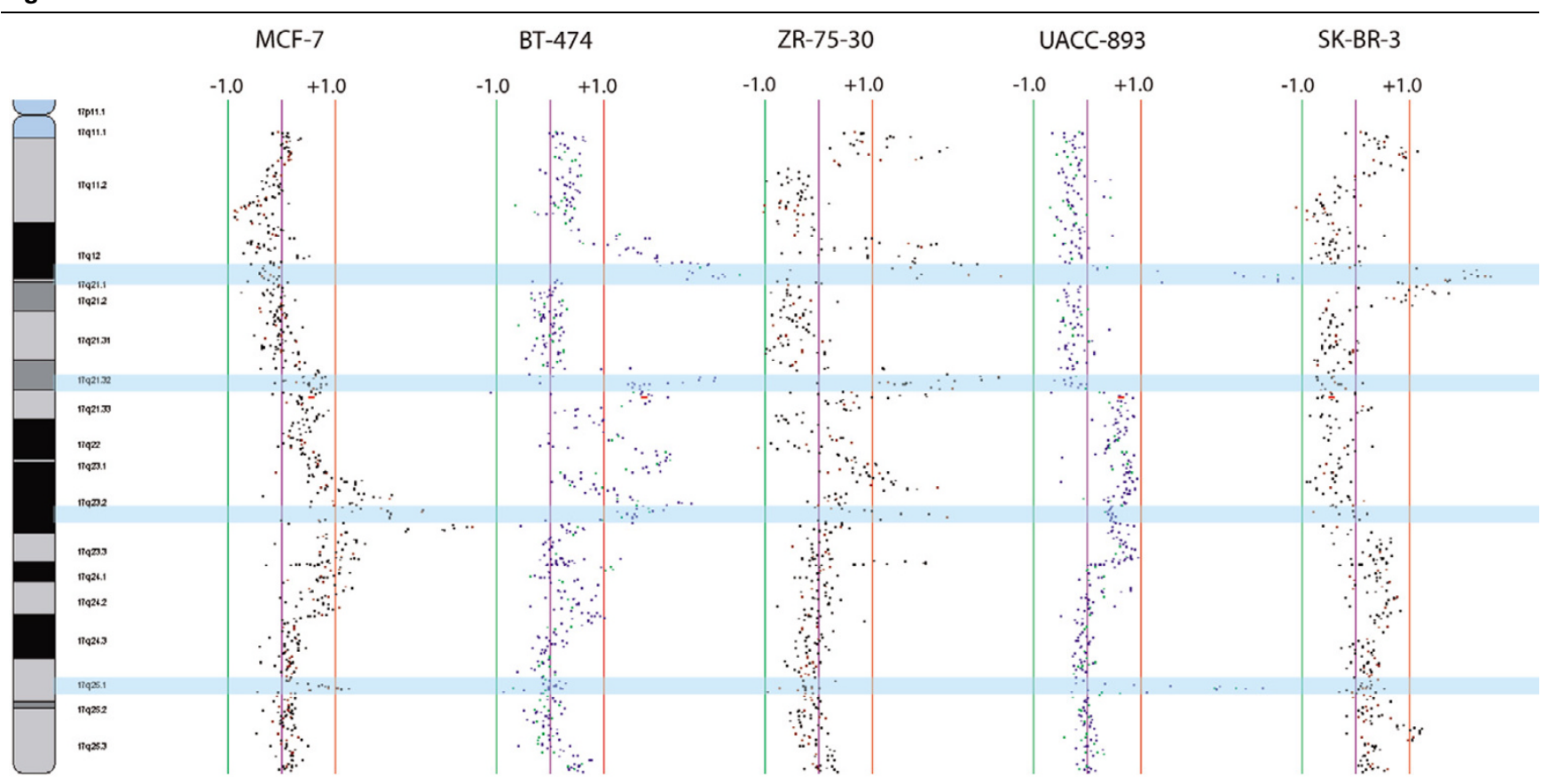

17q SMRT aCGH profile of five cell lines sharing multiple minimum altered regions. Scale bars labelled \pm 1 denote log ${ }_{2}$ ratio scale. Blue highlighted regions indicate the locations of MARs.

containing candidate genes RPS6KB1, LOC51136, FLJ22087, CA4, NY-REN-60, APPBP2 and PPM1D.

Another striking feature identified through our tiling resolution scan of $17 q$ is the overlapping amplicons at $17 q 21.32-q 21.33$ present in BT-474 and ZR-75-30. The $600 \mathrm{~kb}$ MAR from RP11-71G24 to RP11-60007 harbors the HOXB family
(HOXB1 to HOXB9). Previously described by Hyman and colleagues [26], this amplicon is shown to be present in $10.2 \%$ of primary breast cancers, suggesting the involvement of developmental genes in breast cancer pathogenesis (Fig. 4).

Chromosome arm 20q has been shown to be frequently amplified in breast cancer, and amplification of $20 q 13$ is associated 
Breast Cancer Research Vol 8 No 1 Shadeo and Lam

Table 2

Components of the epidermal growth factor receptor pathway affected by copy number change

\begin{tabular}{|c|c|c|c|c|c|c|c|c|}
\hline Gene & Locus & MCF-7 & BT-474 & ZR-75-30 & UACC-893 & Sk-Br-3 & MDA-MB-231 & T47D \\
\hline EGF & $4 q 25$ & & & & & + & & \\
\hline TGFA & $2 p 13.3$ & & - & & & - & & \\
\hline NRG2 & $5 q 31.2$ & & & & & + & & \\
\hline NRG1 & 8p12 & -- & & -- & - & & & \\
\hline EGFR & 7p12.3-p12.1 & & + & & & + & & \\
\hline ErBB2 & $17 q 12$ & & +++ & +++ & +++ & +++ & & \\
\hline ErBB3 & $12 q 13$ & & & & & & & \\
\hline ErBB4 & $2 q 33.3-q 34$ & & & & & & & \\
\hline SH3KBP1 & Xp22.12 & -- & & & & & & \\
\hline RASA2 & $3 q 23$ & & + & & & & & + \\
\hline VAV2 & $9 q 34.2$ & + & + & - & & & & \\
\hline GRB2 & $17 q 25.1$ & ++ & & & +++ & & & \\
\hline PLCG1 & $20 q 12$ & +++ & - & & & & + & + \\
\hline PLCG2 & $16 q 23.2$ & & & - & & - & & + \\
\hline RNTRE & $10 p 14$ & & & & & & & + \\
\hline SSH3BP1 & $10 \mathrm{p} 12.1$ & & & & + & & & \\
\hline SOS1 & $2 p 22.1$ & & - & - & & & & \\
\hline PTK2B & $8 p 21.2$ & - & - & -- & -- & & & \\
\hline SRC & $20 q 11.23$ & & -- & & & +++ & ++ & \\
\hline NRAS & 1p13.2 & +++ & & & - & & & \\
\hline CDC42 & $1 p 36.12$ & & - & & & & & \\
\hline $\mathrm{RAC} 1$ & $7 p 22.1$ & & & & & + & & \\
\hline RIN1 & $11 q 13.2$ & & + & & & & & \\
\hline RAF1 & 3p25.2 & + & & & & & & + \\
\hline MAP3К4 & $6 q 26$ & -- & - & & & & & \\
\hline MAP3K11 & $11 q 13.1$ & + & +++ & & & & & \\
\hline PAK1 & $11 q 13.5$ & & & & & & & + \\
\hline ADAM9 & $8 p 11.23$ & & & & & & & + \\
\hline ADAM12 & $10 q 26.2$ & & --- & & - & & & \\
\hline ADAM17 & $2 p 25.1$ & & + & & & & & \\
\hline RAB5a & 3p24.3 & & & & & + & & \\
\hline MAP2K1 & $15 q 21$ & - & & & & & & \\
\hline MAP2K7 & 19p13.2 & & & - & & & & \\
\hline
\end{tabular}


Table 2 (Continued)

\begin{tabular}{|c|c|c|c|c|c|c|c|c|}
\hline MAP2K4 & $17 q 11.2$ & & & -- & -- & & & \\
\hline MAP2К3 & $17 p 11.2$ & & & - & - & - & & \\
\hline MAP2K6 & $17 q 24.3$ & & +++ & & & + & & + \\
\hline PDPK1 & 16p13.3 & & + & & & & & \\
\hline $\mathrm{CHN} 2$ & $7 p 15.1$ & & + & & + & ++ & & + \\
\hline PRKCA & $17 q 24.2$ & +++ & ++ & & & + & & + \\
\hline ERK1 & $16 p 11.2$ & + & & & & & & \\
\hline ERK2 & $22 q 11.21$ & & & & & - & & \\
\hline MAPK8 & $10 q 11.22$ & & & & & & & + \\
\hline MAPK9 & $5 q 35.3$ & & - & - & & & & \\
\hline MAPK14 & $6 p 21.31$ & & & & & & ++ & \\
\hline AKT1 & $14 q 32.33$ & + & + & & & & & + \\
\hline BAD & $11 q 13.1$ & & +++ & & & & & \\
\hline LIMK1 & $7 q 11.23$ & & + & +++ & & +++ & & + \\
\hline PLD1 & $3 q 26.31$ & & & & & + & & ++ \\
\hline RPS6KA3 & Xp22.12 & - & & & & & & \\
\hline FOS & $14 q 24.3$ & + & & & & & & \\
\hline JUN & 1p32-p31 & - & & & & & & \\
\hline TP53 & 17p13.1 & & + & -- & & & & - \\
\hline MYC & $8 q 24$ & +++ & ++ & +++ & + & +++ & & + \\
\hline ELK1 & Xp11.23 & - & - & & + & & & \\
\hline JUN & 1 p32.1 & - & & & & & & \\
\hline EGF & $4 q 25$ & & & & & + & & \\
\hline
\end{tabular}

Scores:,$+ \log _{2}$ ratio +0.4 to $+0.7 ;++, \log _{2}$ ratio +0.7 to $+0.99 ;+++, \log _{2}$ ratio more than $+1.0 ;-, \log _{2}$ ratio -0.4 to $-0.7 ;--, \log _{2}$ ratio -0.7 to -0.99 ; ,$--- \log _{2}$ ratio less than -1.0 .

with aggressive tumor phenotype, disease recurrence and reduced duration of survival [20]. We identified multiple copy number alterations within this cytoband and defined distinct minimal regions of alteration (Additional file 11). The detection of a 1.5 Mb MAR at 20q13.2 in MCF-7, BT-474 and SK-BR-3 (RP11-20J8 to RP11-346B3) containing the genes encoding zinc finger protein 217 (ZNF217), breast cancer-amplified sequence 1 (BCAS1), cytochrome P450 24A1 (CYP24A1), prefolding 4 (PFDN4) and docking protein 5 (DOK5) is consistent with previous $\mathrm{CGH}$ studies that identified amplification of this region in breast cancer [18,19]. Similarly, we identified a MAR at 20q13.31 from RP11-44A6 to RP11-671P16, containing the gene encoding bone morphogenic protein 7 (BMP7), SPO11 and the gene encoding RNA export 1 (RAE1), corresponding to a previous report in MCF-7 and BT474 [43]. A large $1.5 \mathrm{Mb}$ amplification at 20q13.12 has also been reported in MCF-7 and BT-474 [43]. Our analysis iden- tified an amplification at 20q13.12-q13.13 common to MCF7, BT-474 and SK-BR-3. This spanned BAC clones RP11702E3 to RP11-637D22 defining a narrow 680 kb MAR implicating the genes encoding protein kinase $\mathrm{C}$-binding protein (PRKCBP1) and nuclear receptor coactivator (NCOA3) as potential oncogenes relevant to breast cancer.

\section{EGFR (ERBB1) and associated pathways}

The EGFR and associated pathways have an important role in several aspects of mammalian cell growth such as cell survival, proliferation and differentiation [55,56]. The receptor family is composed of four type-1 tyrosine kinases (ERBB1 to ERBB4) that dimerize after stimulation by ligand and initiate downstream signaling. Receptor ligand recognition is redundant to some extent, and affinity varies. Although ERBB2 has no known ligand, it becomes activated after heterodimerization with other ERBB family members, the most preferred and 
potent combination being with ERBB1, whereas the ERBB3 homodimer remains inactive [57].

The redundancy of this pathway suggests its importance as cells have invested in the mechanisms to make this regulatory pathway fail safe. We have investigated genomic loci for about 60 genes implicated in this pathway (Table 2) [56]. Overall, gains were 2.4 times more frequent than losses, and all cell lines contained at least three loci of change. Our data revealed that, as expected, the ERBB2 locus is highly amplified in four cell lines (UACC-893, ZR-75-30, BT-474 and SK-BR-3), and overexpression has been shown in two of them [9]. Although amplification of EGFR-interacting genes RECQL5, H3F3B and GRB2 has been described above, other frequently altered loci include c-MYC, LIMK1, PRCKA, CHN2, ERBB2, PYK2, $M A P 2 K 3, M A P 2 K 3$ and PLG1. Interestingly, T-47D and the two ERBB2-overexpressing lines, BT-474 and SK-BR-3, share amplifications at five gene loci: MAP2K6, CHN2, PRKCA, LIMK1 and C-MYC.

\section{Conclusion}

We examined the genomes of seven commonly used breast cancer cell models in unprecedented detail for segmental copy number status, cataloging the boundaries of gains and losses throughout these genomes. In addition, we demonstrated that copy number alteration of multiple genetic loci involved in the EGF family of pathways is common in these cell lines, which suggests that disruption of this frequently dysregulated pathway in breast cancer may occur at several points in the signaling cascade and that several disruptions may occur in combination.

Furthermore, because these cell lines serve as models for studying the molecular biology of breast cancer, it is essential to take into account the potential influence of genetic alterations when interpreting biological data. For example, using these lines to study the EGF family of pathways, multiple endogenous genetic alterations may have a role in biochemical and biological observations. Our work provides a comprehensive list of high-level segmental gains and losses for each genome, providing a database of copy number alterations as a resource for breast cancer research with these cell lines.

\section{Competing interests}

The authors declare that they have no competing interests.

\section{Authors' contributions}

AS performed the array CGH experiments, data analysis and drafted the manuscript. WLL is the Principal Investigator. Both authors participated in the development of concepts and framework for the manuscript, the generation of figures, multiple rounds of text editing, and fact checking. Both authors read and approved the final manuscript.

\section{Additional files}

The following Additional files are available online:

\section{Additional File 1}

A Microsoft Word file containing the detailed SMRT array CGH protocol.

See http://www.biomedcentral.com/content/ supplementary/bcr1370-S1.doc

\section{Additional File 2}

A PDF file containing a BT474 Karyogram.

See http://www.biomedcentral.com/content/ supplementary/bcr1370-S2.pdf

\section{Additional File 3}

A PDF file containing a MCF7 Karyogram. See http://www.biomedcentral.com/content/ supplementary/bcr1370-S3.pdf

\section{Additional File 4}

A PDF file containing a T47D Karyogram. See http://www.biomedcentral.com/content/ supplementary/bcr1370-S4.pdf

\section{Additional File 5}

A PDF file containing a SKBR3 Karyogram. See http://www.biomedcentral.com/content/ supplementary/bcr1370-S5.pdf

\section{Additional File 6}

A PDF file containing a MDA MB 231 Karyogram. See http://www.biomedcentral.com/content/ supplementary/bcr1370-S6.pdf

\section{Additional File 7}

A PDF file containing a ZR 7530 Karyogram. See http://www.biomedcentral.com/content/ supplementary/bcr1370-S7.pdf

\section{Additional File 8}

A PDF file containing a frequency plot of 7 cell lines. See http://www.biomedcentral.com/content/ supplementary/bcr1370-S8.pdf

\section{Additional File 9}

A PDF file containing an SNP SMRT aCGH comparison of $4 q$ and $17 q$ in BT474.

See http://www.biomedcentral.com/content/ supplementary/bcr1370-S9.pdf

\section{Additional File 10}

A PDF file containing a multiple alignment of $8 q$. See http://www.biomedcentral.com/content/ supplementary/bcr1370-S10.pdf 


\section{Additional File 11}

A PDF file containing a multiple alignment of $20 q$.

See http://www.biomedcentral.com/content/

supplementary/bcr1370-S11.pdf

\section{Acknowledgements}

We thank Chad Malloff and Jonathan Davies for their guidance in data analysis and manuscript preparation, Sean Minaker and Teresa Mas-

tracci for providing interphase slides, and Carol Cheng for her technical assistance. This work was supported by funds from Genome Canada/ Genome British Columbia.

\section{References}

1. Parkin DM, Bray F, Ferlay J, Pisani P: Global cancer statistics, 2002. CA Cancer J Clin 2005, 55:74-108.

2. Bray F, McCarron P, Parkin DM: The changing global patterns of female breast cancer incidence and mortality. Breast Cancer Res 2004, 6:229-239.

3. Simpson PT, Reis-Filho JS, Gale T, Lakhani SR: Molecular evolution of breast cancer. J Pathol 2005, 205:248-254.

4. Hanahan D, Weinberg RA: The hallmarks of cancer. Cell 2000, 100:57-70.

5. Garnis C, Buys TP, Lam WL: Genetic alteration and gene expression modulation during cancer progression. Mol Cancer 2004, 3:9.

6. Kallioniemi OP, Kallioniemi A, Kurisu W, Thor A, Chen LC, Smith HS, Waldman FM, Pinkel D, Gray JW: ERBB2 amplification in breast cancer analyzed by fluorescence in situ hybridization. Proc Natl Acad Sci USA 1992, 89:5321-5325.

7. Shimada M, Imura J, Kozaki T, Fujimori T, Asakawa S, Shimizu N, Kawaguchi R: Detection of Her2/neu, c-MYC and ZNF217 gene amplification during breast cancer progression using fluorescence in situ hybridization. Oncol Rep 2005, 13:633-641.

8. Jarvinen TA, Tanner M, Rantanen V, Barlund M, Borg A, Grenman $\mathrm{S}$, Isola J: Amplification and deletion of topoisomerase Ilalpha associate with ErbB-2 amplification and affect sensitivity to topoisomerase II inhibitor doxorubicin in breast cancer. $\mathrm{Am} \mathrm{J}$ Pathol 2000, 156:839-847.

9. Lacroix M, Leclercq G: Relevance of breast cancer cell lines as models for breast tumours: an update. Breast Cancer Res Treat 2004, 83:249-289.

10. Emens LA, Davidson NE: Trastuzumab in breast cancer. Onco/ogy (Williston Park) 2004, 18:1117-1128.

11. Baselga J: Herceptin alone or in combination with chemotherapy in the treatment of HER2-positive metastatic breast cancer: pivotal trials. Oncology 2001, 61(Suppl 2):14-21.

12. Vogel CL, Cobleigh MA, Tripathy D, Gutheil JC, Harris LN, Fehrenbacher L, Slamon DJ, Murphy M, Novotny WF, Burchmore M, et al.: First-line Herceptin monotherapy in metastatic breast cancer. Oncology 2001, 61(Suppl 2):37-42.

13. Kallioniemi A, Kallioniemi OP, Piper J, Tanner M, Stokke T, Chen L, Smith HS, Pinkel D, Gray JW, Waldman FM: Detection and mapping of amplified DNA sequences in breast cancer by comparative genomic hybridization. Proc Natl Acad Sci USA 1994, 91:2156-2160.

14. Kytola S, Rummukainen J, Nordgren A, Karhu R, Farnebo F, Isola J, Larsson C: Chromosomal alterations in 15 breast cancer cell lines by comparative genomic hybridization and spectral karyotyping. Genes Chromosomes Cancer 2000, 28:308-317.

15. Forozan F, Mahlamaki EH, Monni O, Chen $Y$, Veldman R, Jiang $Y$, Gooden GC, Ethier SP, Kallioniemi A, Kallioniemi OP: Comparative genomic hybridization analysis of 38 breast cancer cell lines: a basis for interpreting complementary DNA microarray data. Cancer Res 2000, 60:4519-4525.

16. Davies JJ, Wilson IM, Lam WL: Array CGH technologies and their applications to cancer genomes. Chromosome Res 2005, 13:237-248.
17. Pinkel D, Albertson DG: Array comparative genomic hybridization and its applications in cancer. Nat Genet 2005, 37(Suppl):S11-17.

18. Collins C, Volik S, Kowbel D, Ginzinger D, Ylstra B, Cloutier T, Hawkins T, Predki P, Martin C, Wernick M, et al:: Comprehensive genome sequence analysis of a breast cancer amplicon. Genome Res 2001, 11:1034-1042.

19. Albertson DG, Ylstra B, Segraves R, Collins C, Dairkee SH, Kowbel D, Kuo WL, Gray JW, Pinkel D: Quantitative mapping of amplicon structure by array CGH identifies CYP24 as a candidate oncogene. Nat Genet 2000, 25:144-146.

20. Hodgson JG, Chin K, Collins C, Gray JW: Genome amplification of chromosome 20 in breast cancer. Breast Cancer Res Treat 2003, 78:337-345.

21. Orsetti $B$, Nugoli $M$, Cervera N, Lasorsa L, Chuchana $P$, Ursule $L$, Nguyen C, Redon R, du Manoir S, Rodriguez C, et al.: Genomic and expression profiling of chromosome 17 in breast cancer reveals complex patterns of alterations and novel candidate genes. Cancer Res 2004, 64:6453-6460.

22. Albertson DG: Profiling breast cancer by array CGH. Breast Cancer Res Treat 2003, 78:289-298.

23. Nessling M, Richter K, Schwaenen C, Roerig P, Wrobel G, Wessendorf S, Fritz B, Bentz M, Sinn HP, Radlwimmer B, et al:: Candidate genes in breast cancer revealed by microarraybased comparative genomic hybridization of archived tissue. Cancer Res 2005, 65:439-447.

24. Kauraniemi $P$, Barlund $M$, Monni $O$, Kallioniemi $A$ : New amplified and highly expressed genes discovered in the ERBB2 amplicon in breast cancer by cDNA microarrays. Cancer Res 2001 , 61:8235-8240.

25. Monni O, Barlund M, Mousses S, Kononen J, Sauter G, Heiskanen $M$, Paavola P, Avela K, Chen Y, Bittner ML, et al: Comprehensive copy number and gene expression profiling of the 17q23 amplicon in human breast cancer. Proc Natl Acad Sci USA 2001, 98:5711-5716.

26. Hyman E, Kauraniemi P, Hautaniemi S, Wolf M, Mousses S, Rozenblum E, Ringner M, Sauter G, Monni O, Elkahloun A, et al.: Impact of DNA amplification on gene expression patterns in breast cancer. Cancer Res 2002, 62:6240-6245.

27. Clark J, Edwards S, John M, Flohr P, Gordon T, Maillard K, Giddings I, Brown C, Bagherzadeh A, Campbell C, et al.: Identification of amplified and expressed genes in breast cancer by comparative hybridization onto microarrays of randomly selected cDNA clones. Genes Chromosomes Cancer 2002, 34:104-114

28. Pollack JR, Sorlie T, Perou CM, Rees CA, Jeffrey SS, Lonning PE, Tibshirani R, Botstein D, Borresen-Dale AL, Brown PO: Microarray analysis reveals a major direct role of DNA copy number alteration in the transcriptional program of human breast tumors. Proc Natl Acad Sci USA 2002, 99:12963-12968.

29. Ishkanian AS, Malloff CA, Watson SK, DeLeeuw RJ, Chi B, Coe BP, Snijders A, Albertson DG, Pinkel D, Marra MA, et al.: A tiling resolution DNA microarray with complete coverage of the human genome. Nat Genet 2004, 36:299-303.

30. de Leeuw RJ, Davies JJ, Rosenwald A, Bebb G, Gascoyne RD, Dyer MJ, Staudt LM, Martinez-Climent JA, Lam WL: Comprehensive whole genome array CGH profiling of mantle cell lymphoma model genomes. Hum Mol Genet 2004, 13:1827-1837.

31. Watson SK, deLeeuw RJ, Ishkanian AS, Malloff CA, Lam WL: Methods for high throughput validation of amplified fragment pools of BAC DNA for constructing high resolution CGH arrays. BMC Genomics 2004, 5:6.

32. Chi B, DeLeeuw RJ, Coe BP, MacAulay C, Lam WL: SeeGH - a software tool for visualization of whole genome array comparative genomic hybridization data. BMC Bioinformatics 2004 , $5: 13$

33. ArrayCGH [http://www.arraycgh.ca]

34. Jong K, Marchiori E, Meijer G, Vaart AV, Ylstra B: Breakpoint identification and smoothing of array comparative genomic hybridization data. Bioinformatics 2004, 20:3636-3637.

35. VU Micro-Array Data Analysis [http://www.few.vu.nl/ vumarray/

36. Henderson L, Lestou VS, Ludkovski O Robichaud M, Chhanabhai M, Gascoyne RD, Klasa RJ, Connors JM, Marra MA, Horsman DE, et al:: Delineation of a minimal region of deletion at 6q16.3 in follicular lymphoma and construction of a bacterial artificial 
chromosome contig spanning a 6-megabase region of 6q16q21. Genes Chromosomes Cancer 2004, 40:60-65.

37. Savinainen KJ, Linja MJ, Saramaki OR, Tammela TL, Chang GT, Brinkmann AO, Visakorpi T: Expression and copy number analysis of TRPS1, EIF3S3 and MYC genes in breast and prostate cancer. Br J Cancer 2004, 90:1041-1046.

38. Rummukainen J, Kytola S, Karhu R, Farnebo F, Larsson C, Isola JJ: Aberrations of chromosome 8 in 16 breast cancer cell lines by comparative genomic hybridization, fluorescence in situ hybridization, and spectral karyotyping. Cancer Genet Cytogenet 2001, 126:1-7.

39. Zhao X, Li C, Paez JG, Chin K, Janne PA, Chen TH, Girard L, Minna $\mathrm{J}$, Christiani $\mathrm{D}$, Leo $\mathrm{C}$, et al:: An integrated view of copy number and allelic alterations in the cancer genome using single nucleotide polymorphism arrays. Cancer Res 2004, 64:3060-3071.

40. Maass N, Rosel F, Schem C, Hitomi J, Jonat W, Nagasaki K: Amplification of the BCAS2 gene at chromosome 1p13.3-21 in human primary breast cancer. Cancer Lett 2002, 185:219-223.

41. Oi C, Zhu YT, Chang J, Yeldandi AV, Rao MS, Zhu YJ: Potentiation of estrogen receptor transcriptional activity by breast cancer amplified sequence 2. Biochem Biophys Res Commun 2005, 328:393-398.

42. Nagasaki K, Maass N, Manabe T, Hanzawa H, Tsukada T, Kikuchi $\mathrm{K}$, Yamaguchi K: Identification of a novel gene, DAM1, amplified at chromosome 1p13.3-21 region in human breast cancer cell lines. Cancer Lett 1999, 140(1-2):219-226.

43. Lapuk A, Volik S, Vincent R, Chin K, Kuo WL, de Jong P, Collins C, Gray JW: Computational BAC clone contig assembly for comprehensive genome analysis. Genes Chromosomes Cancer 2004, 40:66-71.

44. Falck J, Coates J, Jackson SP: Conserved modes of recruitment of ATM, ATR and DNA-PKcs to sites of DNA damage. Nature 2005, 434:605-611.

45. Jaquemar D, Schenker T, Trueb B: An ankyrin-like protein with transmembrane domains is specifically lost after oncogenic transformation of human fibroblasts. J Biol Chem 1999, 274:7325-7333.

46. Dantzig AH, Hoskins JA, Tabas LB, Bright $S$, Shepard RL, Jenkins IL, Duckworth DC, Sportsman JR, Mackensen D, Rosteck PR Jr, et al.: Association of intestinal peptide transport with a protein related to the cadherin superfamily. Science 1994, 264:430-433.

47. Ma Y, Pannicke U, Schwarz K, Lieber MR: Hairpin opening and overhang processing by an Artemis/DNA-dependent protein kinase complex in nonhomologous end joining and $V(D) J$ recombination. Cell 2002, 108:781-794.

48. Fletcher GC, Patel S, Tyson K, Adam PJ, Schenker M, Loader JA, Daviet L, Legrain P, Parekh R, Harris AL, et al.: hAG-2 and hAG-3, human homologues of genes involved in differentiation, are associated with oestrogen receptor-positive breast tumours and interact with metastasis gene $\mathrm{C} 4.4 \mathrm{a}$ and dystroglycan. $\mathrm{Br}$ $J$ Cancer 2003, 88:579-585.

49. Snijders AM, Nowak N, Segraves R, Blackwood S, Brown N, Conroy J, Hamilton G, Hindle AK, Huey B, Kimura K, et al:: Assembly of microarrays for genome-wide measurement of DNA copy number. Nat Genet 2001, 29:263-264.

50. Xie D, Jauch A, Miller CW, Bartram CR, Koeffler HP: Discovery of over-expressed genes and genetic alterations in breast cancer cells using a combination of suppression subtractive hybridization, multiplex FISH and comparative genomic hybridization. Int J Oncol 2002, 21:499-507.

51. Watson MB, Bahia H, Ashman JN, Berrieman HK, Drew $P$, Lind MJ, Greenman J, Cawkwell L: Chromosomal alterations in breast cancer revealed by multicolour fluorescence in situ hybridization. Int J Oncol 2004, 25:277-283.

52. Barlund M, Tirkkonen M, Forozan F, Tanner MM, Kallioniemi $O$, Kallioniemi A: Increased copy number at 17q22-q24 by CGH in breast cancer is due to high-level amplification of two separate regions. Genes Chromosomes Cancer 1997, 20:372-376.

53. Lowenstein EJ, Daly RJ, Batzer AG, Li W, Margolis B, Lammers R, Ullrich A, Skolnik EY, Bar-Sagi D, Schlessinger J: The SH2 and SH3 domain-containing protein GRB2 links receptor tyrosine kinases to ras signaling. Cell 1992, 70:431-442.

54. Wu GJ, Sinclair CS, Paape J, Ingle JN, Roche PC, James CD, Couch FJ: 17q23 amplifications in breast cancer involve the
PAT1, RAD51C, PS6K, and SIGma1B genes. Cancer Res 2000 60:5371-5375.

55. Bhargava R, Gerald WL, Li AR, Pan Q, Lal P, Ladanyi M, Chen B EGFR gene amplification in breast cancer: correlation with epidermal growth factor receptor mRNA and protein expression and HER-2 status and absence of EGFR-activating mutations. Mod Pathol 2005, 18:1027-1033.

56. Oda K, Matsuoka Y, Funahashi A, Kitano H: A comprehensive pathway map of epidermal growth factor receptor signaling Mol Syst Biol 2005, 1:msb4100014-E1-msb4100014-E17.

57. Graus-Porta D, Beerli RR, Daly JM, Hynes NE: ErbB-2, the preferred heterodimerization partner of all ErbB receptors, is a mediator of lateral signaling. EMBO J 1997, 16:1647-1655. 